\section{A rare case of infectious mononucleosis complicated by Guillain-Barre syndrome}

\author{
Margaret Kennedy, 1 Mariya Apostolova² \\ 1Division of Hematology/Oncology, \\ The Western Pennsylvania Hospital, \\ Pittsburgh, PA; ${ }^{2}$ Department of Internal \\ Medicine, Conemaugh Memorial Medical \\ Center, Johnstown, PA, USA
}

\begin{abstract}
Infectious mononucleosis is a clinical syndrome characterized by fever, lymphadenopathy and pharyngitis. Neurologic complications of infectious mononucleosis, such as the development of Guillain-Barre syndrome, have been rarely reported and usually present late in the course of the disease. We describe a case of a 29 year old male with no significant past medical history who was diagnosed with Guillain-Barre syndrome following an infection with Epstein-Barr virus associated infectious mononucleosis. Supportive treatment resulted in full recovery.
\end{abstract}

\section{Case Report}

A 29 year old white male with an unremarkable past medical history was evaluated at an outpatient setting for sore throat, cough productive of whitish sputum and pink eye. Physical examination at the time revealed several $1 \mathrm{~cm}$ mobile, non-tender cervical lymph nodes. Mild diffuse wheezing was audible on chest auscultation. Chest X-ray showed thickened bronchi and a small calcified nodule in the right lower lobe. No further studies were performed and the patient was sent home with a follow-up visit. Three weeks later the patient reported tingling in his fingertips, toes and lips. The following day his lower extremity tingling sensation had spread to his calves and was soon accompanied by lower extremity weakness. The patient's condition deteriorated to the extent that he was unable to ambulate. He was admitted to the intensive care unit. Upon admission, the patient's temperature was $98.3 \mathrm{~F}$, blood pressure 170/80 $\mathrm{mmHg}$, pulse 82 beats/min and respirations 24 breaths/min. He appeared to be in mild respiratory distress. On physical exam his pupils were equal and reactive to light, sclera were anicteric. Examination of the oropharynx was normal and his thyroid gland was non palpable. Neck was supple and cervical lymphadenopathy was appreciated. Auscultation of the lungs was within normal limits, but he was noted to have shallow breathing. Pulses were palpable throughout. There was no edema, cyanosis or clubbing of the extremities. The skin was dry and no rashes were noted. The spleen and liver were not palpable. On neurological examination the motor power of his upper and lower extremities had decreased significantly, estimated Grade 2 according to the Medical Research Council muscle strength grading system. Deep tendon reflexes were absent throughout. He had mild parasthesia with a symmetric distribution. Based on the history and initial physical exam Guillain-Barre syndrome was strongly suspected.

Initial chemistries were within normal limits. Liver function tests showed albumin of 3.7 $\mathrm{g} / \mathrm{dL}$, total bilirubin of $2.3 \mathrm{mg} / \mathrm{dL}$, alkaline phosphatase of $179 \mathrm{U} / \mathrm{L}$ and aspartamate aminotransferase of $89 \mathrm{U} / \mathrm{L}$. Prothrombin time and activated partial thromboplastin time were within normal limits. CBC revealed white count $10,400 / \mathrm{mm}^{3}$, hemoglobin $15.1 \mathrm{~g} / \mathrm{dL}$, platelets $136,000 / \mathrm{mm}^{3}$. White cell differential was notable for $38 \%$ neutrophils, $7 \%$ lymphocytes, $51 \%$ atypical lymphocytes, 4\% monocytes. Lyme titers were within normal limits. HIV antibody test was negative. Serum antibody titers for cytomegalovirus (CMV), toxoplasma, Hepatitis $\mathrm{B}$ and $\mathrm{C}$ were also negative. Peripheral blood smear showed large atypical lymphocytes-a hallmark finding of infectious mononucleosis. This was followed by heterophile antibody test, which was positive. Immunofluorescence assays of antibody titers to EBV antigens showed absence of EBNA IgG antibodies, Viral Capsid Antigen (VCA) (IgM) of 317 units (normal between 0-90 units), VCA (IgG) of 5 units, suggestive of an acute primary Epstein-Barr virus (EBV) infection.

Lumbar puncture was performed and cerebrospinal fluid revealed white cell count 0 cells/dL, red cell count 4 cells $/ \mathrm{mm}^{3}$, glucose 60 $\mathrm{mg} / \mathrm{dL}$ and protein $56 \mathrm{mg} / \mathrm{dL}$. The findings of the CSF analysis further supported the diagnosis of Guillain-Barre syndrome.

Results from motor and sensory nerve conduction studies on day 5 showed slowing of nerve conduction velocity and prolongation of F-wave latencies, a pattern consistent with demyelinating polyneuropathy. Over the course of the next ten days the patient was treated supportively and received a total of five plasmapheresis treatments, one treatment every other day.

Despite initial deterioration in the patient's respiratory condition, he subsequently improved and did not require mechanical ventilation. He demonstrated progressive recovery of function of his upper extremities. On day eight of his hospital stay he was transferred to the medical service. On day nine he developed a new left facial nerve palsy, from which he later fully recovered. His upper extremities function
Correspondence: Mariya Apostolova, Department of Internal Medicine, Conemaugh Memorial Medical Center, 1086 Franklin Street, Johnstown, PA, USA.

E-mail: maposto1@yahoo.com

Key words: Guillain-Barre syndrome, infectious mononucleosis, atypical lymphocytes, Bell's palsy Epstein-Barr virus.

Conflict of interests: the authors declare no potential conflict of interests.

Received for publication: 18 November 2012. Revision received: 3 April 2013.

Accepted for publication: 8 April 2013.

This work is licensed under a Creative Commons Attribution NonCommercial 3.0 License (CC BYNC 3.0).

CC Copyright M. Kennedy and M. Apostolova, 2013 Licensee PAGEPress, Italy

Neurology International 2013; 5:e7

doi:10.4081/ni.2013.e7

returned back to baseline and he demonstrated marked improvement of the motor and sensory function of his lower extremities. The rest of his hospitalization was uneventful, and he was discharged to a rehabilitation facility on day eighteen.

\section{Discussion}

The present case illustrates all the classical features of infectious mononucleosis (IM) including clinical presentation, findings on peripheral blood smear and heterophile antibody positivity. More than half of the patients diagnosed with IM present with a triad of fever, lymphadenopathy and pharyngitis. ${ }^{1}$ Laboratory studies often reveal thrombocytopenia, leukocytosis, elevated aminotransferases and the presence of heterophile antibodies. ${ }^{1}$ A hallmark finding of acute IM is the expansion of lymphoid cells, collectively termed the atypical lymphocyte population. ${ }^{2}$ The lymphocytes seen represent mostly $\mathrm{T}$ lymphocytes produced in order to target EBVinfected B lymphocytes.1,3 The presence of $10 \%$ atypical lymphocytes on peripheral smear corresponds to $75 \%$ sensitivity and $92 \%$ specificity for the diagnosis of IM. 4 This case highlights the importance of obtaining a peripheral blood smear in a patient with a history of cervical lymphadenopathy and neurological symptoms consistent with the diagnosis of Guillain-Barre syndrome (GBS). Our patient was initially diagnosed with GBS and it was not until the finding of atypical lymphocytes on peripheral smear that a suspicion for the diagnosis of an 
antecedent IM infection was raised.

Neurologic complications during the post infectious state of IM have been rarely reported. 5,6 The initial case reports date back to the early thirties. ${ }^{6}$ In a review of a large case series Silverstein et al. $^{7}$ quoted an incidence of $5.5 \%$. The most common neurological complications of IM include meningitis and meningoencephalitis. Guillain-Barre syndrome is an unusual complication of the disease. ${ }^{2,6}$

Although the exact etiology of GBS remains unclear, the condition is often associated with preceding infections..$^{8,9}$ In 1892, Osler noted an association between bilateral limb weakness and an antecedent febrile infectious illness. ${ }^{10}$ In many instances the pathogen causing the prodromal illness remained unidentified. Etiologic agents of GBS reported in the current literature include CMV, Mycoplasma pneumonia and Campilobacter jejuni.8,9,11-13 A case control study from the Netherlands, quoted C. jejuni as the most commonly identified cause of recent infection in patient with GBS (32\%), followed by CMV, EBV and Mycoplasma pneumonia (13\%, 10\% and 5\% respectively). ${ }^{14}$

The onset of GBS after an episode of EBV infection (with and without an evidence of clinical IM) has been reported and the incidence was estimated to be in the range of 210\%.5,7,9,12,13-19 Grose et al. 16 described five cases of Guillain-Barre syndrome associated with high levels of EBV antibodies. Two of the five patients were also diagnosed with infectious mononucleosis. The authors concluded that there was sufficient evidence to establish an association between IM and GBS. They also reported an association between EBV and GBS even in the absence of IM.

The importance of early treatment in GBS often requires the clinician to make a diagnosis based on history and physical examination without the aid of additional testing. The classic presentation of GBS includes symmetrical ascending motor weakness. ${ }^{2,8}$ Ancillary testing for GBS includes CSF analysis and nerve-conduction studies. Electrophysiologic findings suggestive of GBS include slowing of nerve conduction velocity, prolongation of F-wave latencies and temporal dispersion. ${ }^{8}$ In more than $50 \%$ of the patients CSF examination reveals increased protein levels and normal cell counts. ${ }^{2,8,11}$ However, results from both can be negative in the early stages of the disease. ${ }^{8}$ In our case the diagnosis of GBS was supported by the presence of ascending upper and lower extremity symmetric polyneuropathy, conduction studies and CSF findings.

$\mathrm{EBV}$, a member of the herpesvirus family, was initially discovered in 1964 from cells cultured from a Burkitt's lymphoma patient by Epstein, Achong and Barr.1 The pathophysiology of EBV associated GBS has not been completely elucidated. It has been established that the virus has a predilection for B lymphocytes.
It stimulates polyclonal B cell activation, which in turn results in increased immunoglobulin production. EBV associated infection leads to the development of the demyelinating subtype GBS, while $C$. jejuni associated infection is associated with the axonal subtype GBS. 11 The axonal subtype GBS results from the development of auto antibodies due to molecular mimicry between the bacterial and peripheralnerve components. ${ }^{11}$

Since the identification of EBV as the cause of classic, heterophile positive infectious mononucleosis it has become possible to confirm the disease by specific serologic tests. Due to the fact that EBV like all herpetic viruses causes persistent, lifelong infection, it is important to recognize the patterns seen at different stages of the infection. The first antibodies generated during the course of primary EBV infection are against the VCA complex. The IgM antibodies are transient and the IgG antibodies persist for life. ${ }^{20}$ Later in the course of primary EBV infection, antibodies against the early antigen (EA) complex are generated. These are present transiently and usually disappear after 3 months. ${ }^{20}$ Antibodies against the EBV nuclear antigen (EBNA) complex appear more slowly. In contrast to the kinetics of the antibody responses against VCA and EA, antibodies to EBNA rise during convalescence and then level off. Due to the distinctive kinetics of the different EBV antibody responses, one can often diagnose EBV infection based on a single serum sample. Thus, the presence of IgM and IgG antibodies against VCA and the absence of antibodies to EBNA are diagnostic of a acute EBV infection. ${ }^{20}$ In our case immunofluorescence assays of antibody titers to EBV antigens showed absence of EBNA IgG antibodies, VCA IgM of 317 units and VCA IgG of 5 units, suggestive of the presence of acute primary EBV infection.

Although the association of GBS with facial nerve palsy has been described as a complication of IM, this relationship is not well recognized by clinicians in primary care setting. Bell's palsy following serologically documented IM has been described by Grose et al. who reported 3 cases without other neurological deficits. $^{21}$ Finalizing their discussion, the authors suggested that because of the previously proven association between Bell's palsy, GBS and the presence of EBV infection, it is likely that facial mononeuritis and polyneuritis are variants of the same pathologic process. ${ }^{21}$ Our case confirms that suggestion.

Supportive care is the cornerstone in the management of patients with GBS regardless of its etiology. Due to their anti-inflammatory effect, steroids were initially thought to be beneficial and used to be the treatment of choice. However, several randomized controlled studies that examined the efficacy of steroids in reducing morbidity from GBS have failed to show any significant advantage to their use. ${ }^{8}$ In order to reduce the body's attack to the nervous system treatment modalities such as plasmapheresis and gamma globulin are being used. ${ }^{8}$ Plasma exchange was initially introduced in the 1980 s and treatment benefits have been confirmed in several randomized controlled studies since. 8,11 The value of gamma globulin use was initially reported in the 1990 s. $^{8,10}$ The results from two randomized controlled studies that compared the use of plasmapheresis to the use of IVIG showed both modalities to be equally efficatious. ${ }^{22,23}$ The decision to preferentially use one treatment modality over the other is based on their side effect profiles, the patient's comorbidities and clinical course. Some of the reported side effects of plasmapheresis include hemodynamic instability, abnormal clotting and hypocalcemia. ${ }^{8}$ Significant side effects of gamma globulin include renal failure, myocardial infarction and increased risk of thromboembolism. ${ }^{8}$ Despite the advances in treatment and supportive care the mortality rate in patients diagnosed with GBS is between $3-5 \% .8,11$

\section{Conclusions}

The present case describes the development of two rare neurologic complications of IM in the same patient. The occurrence of both GBS and Bell's palsy within a short time span from the development of EBV associated IM supports the theory that these entities are variants of the same pathologic process. However, this relationship is not well recognized by physicians in the primary care setting or the emergency department. Increased awareness will aid in the timely recognition of the disease complex and the initiation of prompt supportive care. Randomized controlled trials have confirmed the efficacy of plasmapheresis and gamma globulin in the treatment of GBS. Moreover, conducting clinical trials of treatment modalities under development are vital in the effort to improve outcomes in patients with GBS.

\section{References}

1. Cohen JI. Epstein-Barr virus infection. N Engl J Med 2000;343:481-92.

2. Klovstad 0. Guillain-Barre's syndrome in infectious mononucleosis. Acta Med Scand 1950;138:67-70.

3. Tosato G, Magrath I, Koski I, et al. Activation of suppressor $\mathrm{T}$ cells during Epstein-Barr-virus-induced infectious mononucleosis. N Engl J Med 1979;301: 1133-7. 
4. Luzuriaga K, Sullivan JL. Infectious mononucleosis. N Engl J Med 2010;362: 1993-2000.

5. Ricker W, Blumberg A, Peters $\mathrm{CH}$, et al. The association of the Guillain-Barré syndrome with infectious mononucleosis; with a report of two fatal cases. Blood 1947;2:217-26.

6. Klein M. The Guillain-Barré syndrome in infectious mononucleosis; a survey of the literature and study of a fatal case. Confin Neurol 1954;14:232-53.

7. Silverstein A, Steinberg G, Nathanson M. Nervous system involvement in infectious mononucleosis. The heralding and-or major manifestation. Arch Neurol 1972;26: 353-8.

8. Burns TM. Guillain-Barré syndrome. Semin Neurol 2008;28:152-67.

9. Ntziora F, Euthimiou A, Tektonidou M, et al. Guillain-Barre syndrome presenting with sensory disturbance following a herpes virus infection: a case report. J Med Case Rep 2011;5:563.

10. Osler W. The principles and practice of medicine. First edition. New York: Appleron; 1892.

11. Yuki N, Hartung HP. Guillain-Barré syn- drome. N Engl J Med 2012;366:2294-304.

12. Glaser R, Brennan R, Berlin CM. GuillainBarré syndrome associated with EpsteinBarr virus in a cytomegalovirus-negative patient. Dev Med Child Neurol 1979;21: 787-90.

13. Tam CC, O'Brien SJ, Petersen I, et al. Guillain-Barré syndrome and preceding infection with campylobacter, influenza and Epstein-Barr virus in the general practice research database. PLoS One 2007;2: e344.

14. Jacobs BC, Rothbarth PH, van der Meché FG, et al. The spectrum of antecedent infections in Guillain-Barré syndrome: a case-control study. Neurology 1998;51: 1110-5.

15. Takahashi K, Kunishige M, Shinohara M, et al. Guillain-Barré syndrome and hemophagocytic lymphohistiocytosis in a patient with severe chronic active EpsteinBarr virus infection syndrome. Clin Neurol Neurosurg 2005;108:80-3.

16. Grose C, Feorino PM. Epstein-Barr virus and Guillain-Barré syndrome. Lancet 1972;2:1285-7.

17. Wahren B, Link H. Antibodies to EpsteinBarr virus and cytomegalovirus in
Guillain-Barre syndrome. J Neurol Sci 1976;28:129-38.

18. Boyce MJ. E.B. virus and the GuillainBarré syndrome. Lancet 1972;2:1028-9.

19. Grose C, Henle W, Henle G, Feorino PM. Primary Epstein-Barr-virus infections in acute neurologic diseases. N Engl J Med 1975;292:392-5.

20. Paschale M, Clerici P. Serological diagnosis of Epstein-Barr virus infection: problems and solutions. World J Virol 2012; 1:31-43.

21. Grose C, Feorino PM, Dye LA, Rand J. Bell's palsy and infectious mononucleosis. Lancet 1973;2:231-2.

22. van der Meché FG, Schmitz PI. A randomized trial comparing intravenous immune globulin and plasma exchange in GuillainBarré syndrome. Dutch Guillain-Barré Study Group. N Engl J Med 1992;326:11239.

23. Randomised trial of plasma exchange, intravenous immunoglobulin, and combined treatments in Guillain-Barré syndrome. Plasma exchange/sandoglobulin Guillain-Barré syndrome Trial Group. Lancet 1997;349:225-30. 